\title{
Use of DSC in degree of conversion of dimethacrylate polymers: easier and faster than MIR technique
}

\author{
Rafael Turra Alarcon ${ }^{1} \cdot$ Caroline Gaglieri $^{1} \cdot$ Arthur Rossi de Oliveira $^{1} \cdot$ Gilbert Bannach $^{1}$
}

Received: 18 September 2017 / Accepted: 8 January 2018/ Published online: 31 January 2018

(C) Akadémiai Kiadó, Budapest, Hungary 2018

\begin{abstract}
This work aims to determine the degree of conversion of polymers obtained using diurethane dimethacrylate (UDMA) monomer by two different techniques: differential scanning calorimetry (DSC) and Fourier transform infrared spectroscopy (MIR). The measurements were made in triplicate on both equipment, which resulted in average values for MIR $79.52 \pm 3.57 \%$ (camphorquinone photoinitiator) and $78.15 \pm 1.86 \%$ (fluorescein photoinitiator) and for DSC $80.85 \pm 1.06$ and $78.27 \pm 1.71 \%$. The DSC technique showed higher accuracy and lesser standard deviation. Furthermore, this technique is easier and faster than the MIR, and in situ polymerization is not necessary on the DSC equipment.
\end{abstract}

Keywords Photopolymerization - DSC · MIR - Degree of conversion - Techniques comparison - Dimethacrylate

\section{Introduction}

Dimethacrylate monomers are widely used in photopolymerization to produce a high quantity of different materials such as composites, biomaterials, optical materials, and coatings [1-6]. To synthesize these materials, the use of an initiator is necessary, which means a chromophore molecule that is excited by light to generate radicals that initiate the polymerization reaction. A variety of molecules can be used as photoinitiator, such as camphorquinone [7, 8], fluorescein [9], curcumin [10, 11], riboflavin [12, 13], and benzophenone-naphthalimide [14]. Currently, many articles describe the use of Mid-Infrared Spectroscopy (MIR) as a technique to calculate the conversion degree of dimethacrylate monomers [15-17]. Other works describe photo-DSC for this purpose [18, 19], which calculates the energy in photopolymerization process. However, both these techniques require in situ polymerization (on the equipment). Hence, a sensitive technique, which does not require the in situ formation of the polymer, is needed. One alternative is the use of standard DSC, which only requires a previously polymerized sample; moreover, standard DSC

Gilbert Bannach

gilbert@fc.unesp.br

1 Chemistry Department, School of Sciences, São Paulo State University (UNESP), Bauru, SP 17033-260, Brazil is faster and less laborious than MIR analysis. DSC is widely used in thermal characterization of polymers, providing important thermal information such as glass transitions, temperature, enthalpy of fusion, etc. [20-22]; thus, its use to determine the total degree of conversion is additional information. DSC uses the difference of standard enthalpy of bond cleavage $(\mathrm{C}=\mathrm{C})$ and the curve energy (calculated), making it possible to calculate the monomers that remain in the polymers and, consequently, its total degree of conversion.

This work shows the use of standard DSC (not mentioned in the literature before) as an alternative to MIR in the calculation of degree of conversion for dimethacrylate monomers by photopolymerization, the both results techniques were compared by $F$ test, a statistic tool.

\section{Materials and methods}

\section{Preparation of the monomeric mixtures and photopolymerization}

To prepare the monomeric mixtures, Urethane Dimethacrylate (UDMA) (Aldrich) was added to six individual plastic containers, each with $0.01 \mathrm{~mol}$ of the monomer. Two different photoinitiating solutions were prepared by dissolving the photoinitiators (chromophore 
molecule that is excited by light) camphorquinone (CQ) and fluorescein (FL) and ethyl-p-dimethylaminobenzoate (coinitiator, molecule that promotes radical formation) in $10 \mathrm{~mL}$ of acetone at a concentration of $20 \mathrm{mmols}$ of each reagent and added to the reaction mixture (UDMA) at the proportion of $20 \%$ (mol).

The final mixtures containing monomers (UDMA) and initiator system (camphorquinone or fluorescein both with coinitiator) were photopolymerized at room temperature using the light emission equipment D-2000 (DMC Ltd., São Carlos, SP, Brazil), which uses LED to emit blue light $\left(1 \mathrm{~W} \mathrm{~cm}^{-2}\right)$ in the range $430-490 \mathrm{~nm}$, as specified by the manufacturer. The mixtures were placed in a Teflon mold with $1.5 \mathrm{~mm}$ in depth and $3.0 \mathrm{~mm}$ in diameter and were polymerized for $450 \mathrm{~s}$ in triplicate.

\section{Degree of conversion}

\section{Differential scanning calorimetry (DSC)}

DSC curves for each polymer were obtained with a Mettler-Toledo DSC1 Star ${ }^{\mathrm{e}}$ system. Approximately $13 \mathrm{mg}$ of sample were placed in a $40 \mu \mathrm{L}$ closed aluminum crucible with perforated lid. The heating rate was $10{ }^{\circ} \mathrm{C} \mathrm{min}{ }^{-1}$, and

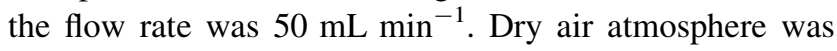
used and the temperature ranged from 150.0 to $220.0^{\circ} \mathrm{C}$. The thermal events observed in the DSC curves were used to calculate the degree of conversion (DC). The $\mathrm{C}=\mathrm{C}$ bond requires $60 \mathrm{~kJ} \mathrm{~mol}^{-1}$ to cleave the $\pi$ ligation, which is considered the standard enthalpy of polymerization $\left(\Delta H_{\text {pol }}\right)$ [23-26]. The energy obtained in polymerization peak in DSC curves of polymers refers to residual monomer in polymers previously photopolymerized $\left(E_{\mathrm{p}}\right)$. It is possible to obtain the DC (\%) from DSC curves using Eq. 1.

DC $(\%)=\left[1-\left(\frac{E_{\mathrm{p}} \cdot \mathrm{MM}}{\Delta H_{\mathrm{pol}} \cdot m_{\mathrm{a}}}\right)\right] \times 100$

Equation 1: formula to calculate the degree of conversion (DC) percentage using the DSC.

$\mathrm{MM}$ is the molar mass of monomer, and $m_{\mathrm{a}}$ is the sample mass used in DSC analysis.

Two previous works described the use of DSC to calculate the degree of conversion of methacrylate monomers $[27,28]$; however, these works just consider the polymerization by temperature using thermoinitiator (benzoyl peroxide and 2,2'-azobizisobutyronitrile), not comparing techniques or mentioning photopolymerization.

\section{Middle infrared spectroscopy (MIR)}

To calculate the degree of conversion for each polymer, a spectrophotometer from Bruker, model Vertex 70, was used. The equipment operated in the range 4000 $400 \mathrm{~cm}^{-1}$. Monomeric mixtures were placed over the diamond crystal and polymerized, while the transmittance (T\%) of each sample was collected. Data collection occurred every $10 \mathrm{~s}$, and 45 measurements were made for all samples (in triplicate). Equation 2 is used to quantify the degree of conversion for each sample $[8,9,11]$.

$\mathrm{DC}(\%)=\left[1-\frac{T_{\mathrm{t}=x}(\mathrm{C}=\mathrm{C})}{T_{\mathrm{t}=0}(\mathrm{C}=\mathrm{C})}\right] \times(-1000)$

Equation 2: formula to calculate the degree of conversion (DC) percentage using the transmittance of double carbon bonds $(\mathrm{C}=\mathrm{C})$ present in the monomer.

Transmittance of the $\mathrm{C}=\mathrm{C}$ bond is seen near the $1640 \mathrm{~cm}^{-1}$ wavenumber. At the initial time $(t=0)$, a minimum transmittance is observed at this wave number, as polymerization has not yet begun. At any other future time $(t=x)$, the transmittance increases, as polymerization takes place and double bonds are cleaved. With this input of data and applying Eq. 2, graphs for degree of conversion over time were plotted.

\section{Statistical analysis}

The results obtained from both techniques were analyzed by $F$ test, following the steps described by the Ref. [29].

\section{Results and discussion}

\section{Degree of conversion}

\section{Middle infrared spectroscopy (MIR)}

The MIR measurements depicted a band near $1640 \mathrm{~cm}^{-1}$, evincing the $\mathrm{C}=\mathrm{C}$ double bond present in the dimethacrylate molecules. As expected, the intensity of this band decreased considerably for the polymers, because this process involved the cleavage of the $\pi$ bond. Hence, it was possible to calculate the conversion degree of each monomer using Eq. 1. Figure 1 shows the degree of conversion for all samples (UDMA with CQ and FL) studied, at different times during polymerization.

Therefore, for the UDMA with CQ and FL photoinitiators, the degree of conversion for the three samples had an average of $79.52 \pm 3.57 \%$ for the CQ system and a conversion average of $78.15 \pm 1.86 \%$ for the FL system.

\section{Differential scanning calorimetry (DSC)}

The DSC curves in Fig. 2 illustrate that all systems exhibited similar thermal behavior: an exothermic peak $\left(187.5^{\circ} \mathrm{C}\right)$ associated to polymerization of residual 
Fig. 1 Degree of conversion curves for UDMA with CQ (a) and UDMA with FL (b)
Fig. 2 DSC curves for UDMA with CQ (a) and UDMA with FL (b)
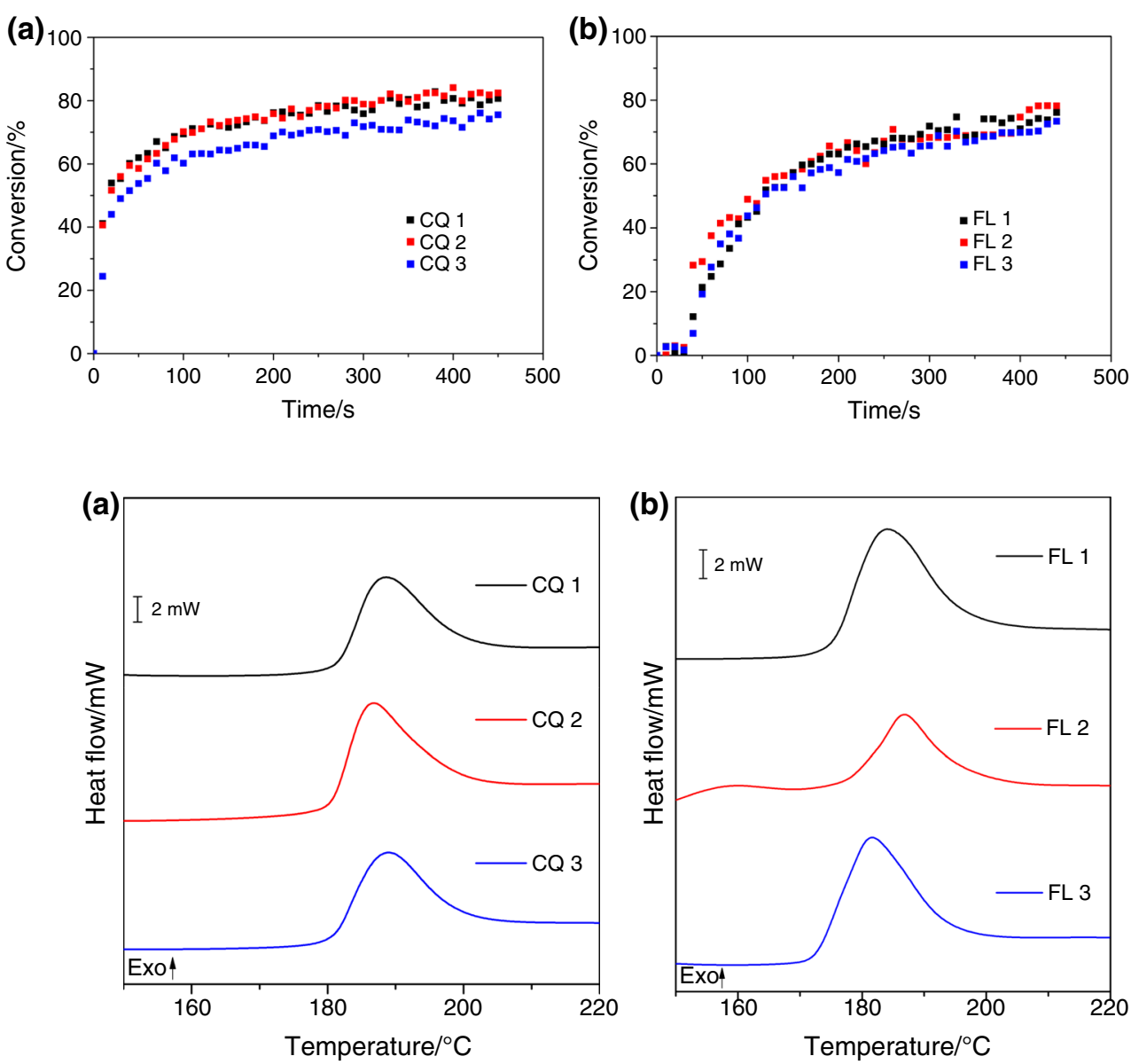

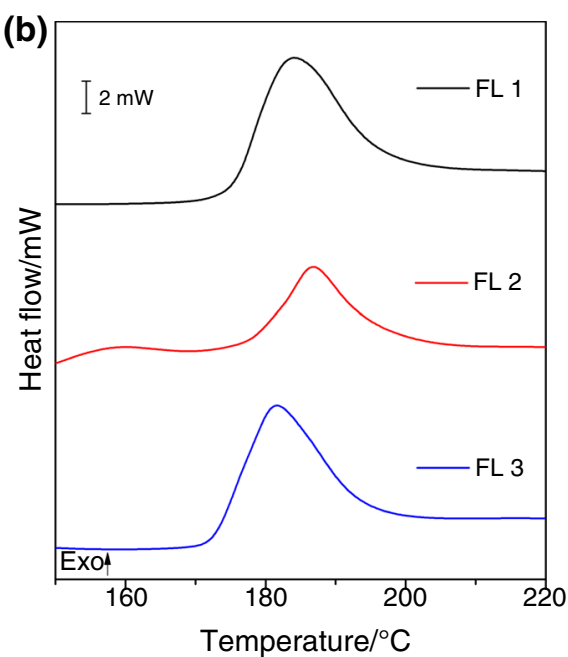

monomers in photopolymerization. The area integration was made according to Fig. 3, and just the middle peak was considered in $E_{\mathrm{p}}$ (Eq. 2). The curve area (marked in blue in Fig. 3) is determined by two points, the first one is the onset (the point that reaction initiate) and endset that was considered the final curve point. The endeset is necessary, due to was not possible determine with accuracy

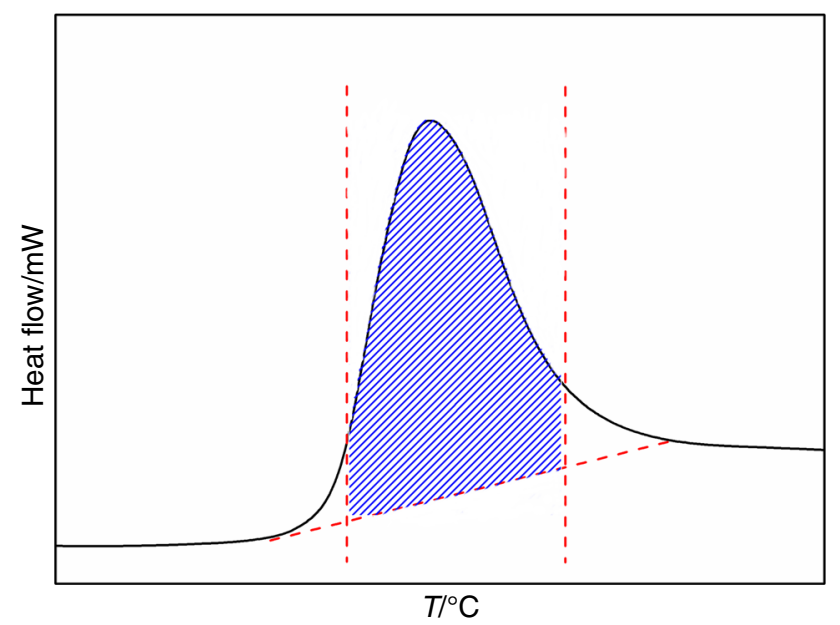

Fig. 3 Representative DSC curve for $E_{\mathrm{p}}$ calculation the end of the reaction, this end process could occur in any point after the maximum peak, this fact is observed in all thermal process in thermal analysis such as polymerization, degradation, phase transition etc.

Finally, the results of DSC measurement showed an average value similar to MIR: $80.85 \pm 1.06 \%$ (CQ) and $78.27 \pm 1.71 \%$ (FL); thus, the standard deviation value in DSC is less than MIR values, which indicates more accurate analyses. This could be because the MIR does not have a sample control such as mass or thickness. The degree of conversion values obtained for each sample for each technique is exhibited in Table 1.

\section{Statistical analysis}

The $F$ test was used to compare the variance values, assuming the confidence interval equal to $95 \%$. All values of $F$ were lower than $F_{\text {critical }}$, demonstrating that the values of both techniques did not distinguish themselves [29]. These results indicate that DSC could be use in determination of the degree of conversion. The statistical data are shown in Table 2. 
Table 1 Values of degree of conversion, average and standard deviation obtained for each sample using DSC and MIR

\begin{tabular}{lllll}
\hline Photoinitiator & Equipment & DC/\% & Average/\% & SD \\
\hline CQ & DSC & 81.49 & 80.85 & 1.06 \\
& & 79.63 & & \\
& & 81.44 & & 3.57 \\
& MIR & 80.65 & 79.52 & \\
FL & 82.39 & & 1.71 \\
& & 75.52 & & \\
& DSC & 77.06 & 78.27 & \\
& & 80.24 & & \\
& & 77.53 & & \\
& MIR & 76.12 & 75.90 &
\end{tabular}

$D C$ degree of conversion, $S D$ standard deviation

Table 2 Values of $F$ and $F_{\text {critical }}$ obtained by the $F$ test

\begin{tabular}{llr}
\hline Initiator & CQ & FL \\
\hline$F$ & 11.4 & 1.9 \\
$F_{\text {critical }}$ & 19.0 & 19.0 \\
\hline
\end{tabular}

\section{Conclusions}

The average values for degree of conversion obtained by DSC and MIR were very similar, and the $F$ test showed that the variance values did not differ. Hence, these results prove that DSC could be an alternative of MIR technique in degree of conversion for dimethacrylate monomers.

The principal advantage of DSC is its accuracy, higher than MIR, as observed in standard deviation values (in both photoinitiator); another advantage that in situ polymerization is not necessary.

Acknowledgements The authors wish to thank CAPES (Proc. 024/2012 Pro-equipment), POSMAT/UNESP, and FAPESP (Processes: 2 2013/09022-7 and 2017/08820-8) for financial support.

\section{References}

1. Fouassier JP, Allonas X, Burguet D. Photopolymerization reactions under visible lights: principle, mechanisms and examples of applications. Prog Org Coat. 2003;47:16-36.

2. Jakubiak J, Nie J, Línden LA, Rabek JF. Crosslinking photocopolymerization of acrylic acid (and $\mathrm{N}$-vinylpyrrolidone) with triethylene glycol dimethacrylate initiated by camphorquinone/ ethyl-4-dimethylaminobenzoate. J Polym Sci Polym Chem. 2001;38:876-86.

3. Lu H, Lovell LG, Bowman CN. Exploiting the heterogeneity of cross-linked photopolymers to create high-Tg polymers from polymerizations performed at ambient conditions. Macromolecules. 2001;34:8021-5.
4. Ye Q, Spencer P, Wang Y, Misra A. Relationship of solvent to the photopolymerization process, properties, and structure in model dentin adhesives. J Biomater Mater Res. 2007;80:342-50.

5. Rodrigues MR, Neumann MG. Fotopolimerização: princípios e métodos. Polim Cienc Tecnol. 2003;13:276-86.

6. Lim KS, Schon BJ, Mekhileri NV, Brown GCJ, Chia CM, Prabakar S, Hooper GJ, Woodfield TBF. New visible-light photoinitiating system for improved print fidelity in gelatin-based bioinks. Biomater Sci Eng. 2016;10:1752-62.

7. Guerra RM, Durán I, Ortiz P. FTIR monomer conversion analysis of UDMA-based dental resins. J Oral Rehabil. 1996;23:632-7.

8. Alarcon RT, Holanda BBC, Rinaldo D, Caires FJ, de Almeida MV, Bannach G. Synthesis, thermal studies and conversion degree of dimethacrylate polymer using new non-toxic coinithiators. Quim Nova. 2017;40:363-70.

9. Alarcon RT, Gaglieri C, da Silva BHST, Silva-Filho LC, Bannach G. New fluorescein derivatives and their use as an efficient photoiniator using blue light LED. J Photochem Photobiol A. 2017;343:112-8.

10. Zhao J, Lalevée J, Lu H, MacQueen R, Kable SH, Schmidt TW, Stenzel MH, Xiao P. A new role of curcumin: as a multicolor photoinitiator for polymers fabrication under household UV to LED bulbs. Polym Chem. 2015;6:5053-61.

11. de Oliveira DSBL, de Oliveira LSBL, Alarcon RT, Holanda $\mathrm{BBC}$, Bannach G. Use of curcumin and glycerol as an effective photoinitiating system in the polymerization of urethane dimethacrylate. J Therm Anal Calorim. 2017;128:1671-82.

12. Encinas MV, Rufus AM, Bertolotti SG, Previtali CM. Free radical polymerization photoinitiated by riboflavin/amines. Effect of the amine structure. Macromolecules. 2001;34:2845-7.

13. Bertolotti SG, Previtali CM, Rufus AM, Encinas MV. Riboflavin/ triethanolamine as photoinitiator system of vinyl polymerization. A mechanistic study by laser flash photolysis. Macromolecules. 1999;32:2920-4.

14. Zhang J, Dumur F, Xiao P, Graff B, Gigmes D, Fouassier JP, Lalevée J. A benzophenone-naphthalimide derivative as versalite photoinitiator of polymerization under near UV and visible lights. J Polym Sci. 2015;553:451-5.

15. Moraes LGP, Rocha RSF, Menegazzo LM, de Araújo EB, Yukimito K, Moraes JCS. Infrared spectroscopy: a tool for determination of the degree of conversion in dental composites. J Appl Oral Sci. 2008;16:145-9.

16. Eliades GC, Vougioklakes GJ, Caputo AA. Degree of double bond conversion in light-cured composites. Dent Mater. 1987;3:18-25.

17. Albuquerque PPAC, Moreira ADL, Moraes RR, Cavalcante LM, Scheider LFJ. Color stability, conversion, water sorption and solubility of dental composites formulated with different photoinitiator systems. Dent Mater. 2013;41:e67-72.

18. Scott TF, Cook WD, Forsythe JS. Photo-DSC cure kinetics of vinyl ester resins. I. Influence of temperature. Polymer. 2002;43:5839-45.

19. Corcione CE, Frigione M, Maffezzoli A, Malucelli G. PhotoDSC and Real time FT-IR kinetic study of a UV curable epoxy resin containing o-Boehmites. Eur Polym J. 2008;44:2010-23.

20. Hatekayama T, Quinn FX. Thermal analysis: fundamentals and applications to polymer science. New York: Willey; 1994.

21. Blom H, Yeh R, Wojnarowski R, Ling M. Detection of degradation of ABS materials via DSC. J Therm Anal Calorim. 2006;83:113-5.

22. Ionashiro M, Caires FJ, Gomes DJ. GIOLITO: fundamentos da termogravimetria e análise térmica diferencial/calorimetria exploratória diferencial. 2nd ed. São Paulo: Giz; 2014.

23. Terrin MA, Horn MA, Neumann MG, Cavalheiro ET, Correa IC, Schimitt CC. Effect of the loading of organomodified clays on the 
thermal and mechanical properties of a model dental resin. Mater Res. 2016;19:40-4.

24. Roberts DE. Heats of polymerization: A summary of published values ant their relation structure. J Res Natl Bur Stand. 1950;44:221-32.

25. Tanimot Y, Hayakawa T, Nemoto K. Analysis of photopolymerization behavior of UDMA/TEGDMA resin mixture and its composite by differential scanning calorimetry. J Biomed. 2004;72B:310-5.

26. Canevarolo-Junior SV. Técnicas de caracterização de polímeros. 1st ed. São Paulo: Artliber Editora; 2007.
27. Miyazaki K, Horibe T. Polymerization of multifunctional methacrylates and acrylates. $\mathrm{J}$ Biomed Mater Res. 1988;22:1011-22.

28. Morgan DR, Kalachandra S, Shobha HK, Gunduz N, Stejskal EO. Analysis of a dimethacrylate copolymer (Bis-GMA and TEGDMA) network by DSC and ${ }^{13} \mathrm{C}$ solution and solid-state NMR spectroscopy. Biomater. 2000;21:1897-903.

29. Miller JN, Miller JC. Statistics and chemometrics for analytical chemistry. 6th ed. Harlow: Pearson Education Limited; 2010. 